\title{
Genomic Binding and Transcriptional Regulation by the Drosophila Myc and Mnt Transcription Factors
}

\author{
A. Orian,* S.S. Grewal, P.S. Knoepfler, B.A. Edgar, S.M. Parkhurst, \\ AND R.N. EISENMAN \\ Division of Basic Sciences, Fred Hutchinson Cancer Research Center, Seattle, Washington 98109-1024
}

\begin{abstract}
Deregulated expression of members of the myc oncogene family has been linked to the genesis of a wide range of cancers, whereas their normal expression is associated with growth, proliferation, differentiation, and apoptosis. Myc proteins are transcription factors that function within a network of transcriptional activators (Myc) and repressors (Mxd/Mad and Mnt), all of which heterodimerize with the bHLHZ protein Mad and bind E-box sequences in DNA. These transcription factors recruit coactivator or corepressor complexes that in turn modify histones. Myc, Mxd/Max, and Mnt proteins have been thought to act on a specific subset of genes. However, expression array studies and, most recently, genomic binding studies suggest that these proteins exhibit widespread binding across the genome. Here we demonstrate by immunostaining of Drosophila polytene chromosome that Drosophila $\mathrm{Myc}(\mathrm{dMyc})$ is associated with multiple euchromatic chromosomal regions. Furthermore, many dMyc-binding regions overlap with regions containing active RNA polymerase II, although dMyc can also be found in regions lacking active polymerase. We also demonstrate that the pattern of dMyc expression in nuclei overlaps with histone markers of active chromatin but not pericentric heterochromatin. dMyc binding is not detected on the X chromosome rDNA cluster (bobbed locus). This is consistent with recent evidence that in Drosophila cells dMyc regulates rRNA transcription indirectly, in contrast to mammalian cells where direct binding of c-Myc to rDNA has been observed. We further show that the dMyc antagonist dMnt inhibits rRNA transcription in the wing disc. Our results support the view that the $\mathrm{Myc} / \mathrm{Max} / \mathrm{Mad}$ network influences transcription on a global scale.
\end{abstract}

Several papers in this volume describe a striking association between genomic alterations involving $m y c$ and different human cancers. Indeed, genetic rearrangements involving the $m y c$ proto-oncogene have long been linked to an extraordinarily wide spectrum of cancers in humans and other animals (for review, see Henriksson and Luscher 1996; Nesbit et al. 1999; Lutz et al. 2002; Popescu and Zimonjic 2002). The notion that myc function is deeply tied to cancer etiology has stimulated a great deal of research on the myc gene and its protein product (Myc).

The proteins encoded by the mammalian myc gene family (c-, N-, L-Myc) are now understood to function as transcription factors through their heterodimerization with the small basic-helix-loop-helix-zipper (bHLHZ) protein Max. Myc-Max heterodimers recognize the Ebox sequence CACGTG with high affinity and activate transcription of synthetic reporter genes and endogenous cellular genes that contain promoter-proximal E-boxbinding sites (for recent reviews, see Grandori et al. 2000; Amati et al. 2001; Eisenman 2001; Oster et al. 2002). Myc-Max heterodimers also associate with the BTB-POZ domain protein Miz-1 and inhibit trans-activation of Miz-1 target genes (Seoane et al. 2001; Staller et al. 2001; Herold et al. 2002). Other modes of transcriptional repression by Myc have also been reported (Brenner et al.

*Present address: Center for Cancer and Vascular Biology, Rappaport Institute for Medical Research, and the Ruth and Bruce Rappaport Faculty of Medicine, Technion-Israel Institute of Technology, P.O.Box 9649, Bat.Galim Haifa 31096, Israel.
2005; for review, see Adhikary and Eilers 2005; KleineKohlbrecher et al. 2006).

Myc-Max heterodimers also function within the context of an interesting group of antagonists. These include the Max-binding proteins Mxd1-4 (formerly known as Mad1, Mxi1, Mad3, and Mad4, www.gene.ucl.ac.uk/ nomenclature/) and Mnt. These proteins heterodimerize with Max and also recognize the CACGTG E-box sequence. However, the Mxd-Max and Mnt-Max heterodimers repress transcription at these E-box-binding sites and thus act as at least partial antagonists of MycMax trans-activation function (for review, see Eisenman 2001; Luscher 2001; Zhou and Hurlin 2001; Rottmann and Luscher 2006).

The transcriptional activities of the Myc and Mxd/Mnt proteins are governed by their interactions with higher-order complexes. The highly conserved and functionally essential Myc Box II region of Myc family proteins associates with the TRRAP coactivator, which in turn recruits the Tip60/Tip48/Tip49 and GCN5 histone acetyltransferases (HAT). Other regions of Myc bind the HATs p300 and CBP. Furthermore, components of chromatin-remodeling complexes such as BAF53 and INI1 have also been reported to associate with Myc (for review, see Cole and Nikiforov 2006). The recruitment of putative activating complexes by Myc can be contrasted with the recruitment of repression complexes by the Mxd/Mnt proteins. A small amphipathic helical region (SID) near the amino terminus of all Mxd and Mnt family proteins interacts specifically with a conserved domain within the corepressors mSin3A and mSin3B (Ayer et al. 1995; Schreiber-Agus et al. 1995; Brubaker et al. 2000). This interaction is respon- 
sible for Mxd repression (Cowley et al. 2004). The Sin3 proteins function to recruit class I histone deacetylases (HDACs) and other factors also likely to be involved in transcriptional repression. The associations of Myc and $\mathrm{Mxd} / \mathrm{Mnt}$ proteins with higher-order coactivator and corepressor complexes suggests that the transcriptional activities of Myc and Mxd/Mnt are due at least in part to histone modifications mediated by the recruited HATs and HDACs. Consistent with this are findings demonstrating that binding of Myc to its target genes results in increased acetylation in the vicinity of the binding site (Frank et al. 2001), whereas Mxd1 (Mad1) binding leads to histone deacetylation (Bouchard et al. 2001; for review, see Amati et al. 2001; Cole and Nikiforov 2006).

\section{ORTHOLOGS OF Myc, Max, AND Mnt GENES IN DROSOPHILA}

Identification and analysis of myc, max, and $m x d / m n t$ homologs in Drosophila melanogaster (denoted dmyc, $d$ max, and dmnt, respectively) have proven useful in revealing the functions of these genes in both flies and vertebrates (Gallant et al. 1996; Schreiber-Agus et al. 1997; Loo et al. 2005; for recent review, see Gallant 2006). Drosophila possesses only one version of each gene, in contrast to the extensive vertebrate myc and mad gene families, thereby facilitating genetic analysis. Like their vertebrate orthologs, the dMyc and dMnt proteins heterodimerize with dMax, bind CACGTG, and activate (in the case of dMyc-dMax) or repress (in the case of dMntdMax) transcription. In addition, dmyc has been demonstrated to effectively rescue proliferation in c-myc null cells (Trumpp et al. 2001; and our unpublished data) and cotransforms primary rat embryo cells (Schreiber-Agus et al. 1997). dmyc is an essential gene involved in cell growth and endoreplication, oogenesis, and apoptosis (Gallant et al. 1996; Schreiber-Agus et al. 1997; Johnston et al. 1999; Maines et al. 2004; Pierce et al. 2004). dmnt has recently been shown to be a nonessential gene that functions to limit cell growth (Loo et al. 2005). In addition to conservation of the Max network components themselves, key elements of the machinery that regulates their function are also conserved. For example, mammalian Myc proteins are targeted for ubiquitination and proteasome-dependent degradation by the Fbw7-SCF complex (Welcker et al. 2004a,b; Yada et al. 2004) whereas in Drosophila the Fbw7 homolog Archipelago carried out the same function for dMyc (Moberg et al. 2004). Interestingly, although the ubiquitin ligase Skp2 has been suggested to target mammalian Myc for degradation (Kim et al. 2003; von der Lehr et al. 2003), the Skp2 homolog in flies is not involved in turnover of dMyc (Moberg et al. 2004).

\section{WIDESPREAD GENOMIC BINDING BY DROSOPHILA Myc/Max/Mnt PROTEINS}

A major problem in understanding Myc function in both normal and neoplastic cells has been to delineate the number and nature of the genes that it regulates. Because Myc expression or overexpression causes profound ef- fects on multiple cellular processes, it is not surprising that expression microarray studies have collectively identified Myc-associated expression changes in a large number ( $\sim 5 \%)$ of cellular genes (see Zeller et al. 2003; for an updated list of Myc target genes, see www.myc-cancergene.org/). Modulation of the expression of many of these genes might be considered as only due to an indirect or downstream effect of Myc on the biology of the cell. However, regulation of a large number of these genes by the inducible Myc-ER system was insensitive to cycloheximide, suggesting that Myc is directly influencing their expression.

To define genomic binding sites for Myc, we employed the recently described DamID method (van Steensel and Henikoff 2000; van Steensel et al. 2001, 2003; Greil et al. 2003). In this approach, a DNA-binding protein is fused to the bacterial DNA adenine methyltransferase (Dam). Such fusion proteins have been previously shown to methylate adenine in the sequence GATC within 1.5-2 $\mathrm{kb}$ of the binding site (van Steensel and Henikoff 2000). The location of the factor-binding sites can be determined by methylation-sensitive restriction enzyme cleavage of the genomic DNA followed by microarray analysis. In our experiments, we expressed low levels of either DamdMyc, dMax-Dam, or dMnt-Dam in Drosophila Kc cells and isolated $0.1-2 \mathrm{~kb}$ DNA fragments produced by digestion with $D p n I$ (which cuts only at G- ${ }^{\mathrm{m} 6} \mathrm{~A}-\mathrm{T}-\mathrm{C}$, the target sequence for Dam methylation). The Cy5 fluorochrome-labeled DNA fragments from cells expressing the Dam fusion proteins were mixed with Cy3-labeled fragments isolated from cells expressing Dam alone and hybridized to a Drosophila cDNA array containing 6255 cDNAs and ESTs. The Cy5:Cy3 fluorescence ratio from multiple experiments was used to establish a statistically significant set of targeted regions. We found that $15.4 \%$ of Drosophila coding regions (968 of 6255 elements on the array) were associated with one or more of the three dMax-network proteins (Orian et al. 2003). Interestingly, whereas many genomic loci exhibit binding by the three network proteins, a significant number of loci appeared to be targets for a subset of the network factors (see below). $\mathrm{dMyc} / \mathrm{dMax} / \mathrm{dMnt}$-binding sites are extensively distributed over the four major Drosophila chromosomes. However, binding was not random-repetitive elements often associated with pericentric heterochromatin and HP1 binding (the latter also determined using the DamID assay [van Steensel et al. 2001]) were largely devoid of dMyc/dMax/dMnt-binding signal. Furthermore, statistical analysis demonstrated that binding by these factors strongly correlates with the presence of the E-box sequence CACGTG, the previously determined binding site for Myc network proteins (see above). Significant association of dMyc-binding sites with the E-box sequences only occurred in the presence of coexpressed dMax. Other sequence motifs also appear to correlate with binding. These include the binding sites for DREF (DNA replication element factor), the transcription factor Cut, and BEAF32 (a boundary element-associated factor). It remains unclear what role the association of Max network proteins with these sites might play. However, given, for example, the well-established association of mammalian 
Myc-Max heterodimers with Miz-1, it is likely that association of dMyc and dMnt with other factors, either as heterodimers with Max or as monomers, could direct the targeting of dMax network proteins to non-E-box sites.

Because a large fraction (48.6\%) of the genes found associated with all three dMax network proteins displayed altered expression in response to dMyc in microarray analysis of third-instar larvae (Orian et al. 2003), it seems likely that many of the binding regions are functional. Binding regions that do not correspond to genes displaying altered expression may represent genes whose expression is simply not regulated in the larval stage analyzed, perhaps because cooperating factors, as yet unknown, are absent. Alternatively, binding at a particular site could serve another purpose.

\section{LOCALIZATION OF dMyc BY IMMUNOSTAINING OF DROSOPHILA POLYTENE CHROMOSOMES}

An important finding of the DamID study is the extensive binding displayed by the dMax network proteins. Nonetheless, our assessment that $15 \%$ of Drosophila genes are bound by dMax network members is likely to be an underestimate because the array used in our analysis contained cDNAs, thus permitting detection only of binding segments that happen to overlap with an encoded region. Binding of dMax network proteins to intergenic, intronic, or upstream promoter regions would not have been detected in the assay. To obtain another view of dMyc association with genomic DNA, we used an anti-dMyc polyclonal antibody to immunostain Drosophila polytene chromosomes (see Bianchi-Frias et al. 2004). Figure 1A shows dMyc (red) and DAPI (blue) staining of a third-instar larval salivary gland chromosome. dMyc appears to be bound to multiple chromosomal segments throughout the length of the chromosome and, in general, appears to be associated with most interband regions. The dense DAPI bands largely represent more condensed chromatin domains. Figure 1B shows staining by antibody against the Hairy transcription factor, another bHLH class protein. Hairy binding is intense in several regions but is considerably less widespread than $\mathrm{dMyc}$, a conclusion supported by the merged images (Fig. 1C) as well as by a DamID study with Hairy (Bianchi-Frias et al. 2004). A more detailed image of a more fully spread anti-dMyc stained chromosome is shown is Figure 1D (green). Co-staining of the chromosome with antibody against phosphorylated Ser-5 within the carboxy-terminal domain (CTD) of RNA polymerase II (red) is shown in Figure 1E, with merged images in Figure 1F. This phosphorylated form of RNA polymerase II (Upstate Biotechnology) is associated with an actively transcribing form of the polymerase. It is evident that both the phospho-CTD staining and the dMyc staining occur extensively throughout the chromosome, again in interband, less condensed, regions and that there is considerable overlap between dMyc and active RNA polymerase II. However, there is also clear evidence of anti-dMyc staining to regions that do not stain with antiphospho-CTD (Fig. 1F merged image and Fig. $1 \mathrm{~F}^{\prime}$, higher magnification merged image). This is consistent with the comparison between the larval expression array data and the DamID-binding data mentioned above and provides support for the notion that $\mathrm{dMyc}$ can interact with regions that are not constitutively transcribed.

\section{dMyc ASSOCIATES WITH REGIONS OF ACTIVE CHROMATIN}

The association of dMyc binding with coding regions in the DamID experiments, as well as detection of dMyc and active RNA polymerase II in interband, non-heterochromatic regions of polytene chromosomes, suggests that $\mathrm{dMyc}$ is largely present in regions of active chromatin. To further explore this idea, we carried out immunostaining with antibodies against acetylated Lys- 9 in histone H3 (H3-Ac-K9) and dimethyl Lys-9 in histone H3 (H3-diME-K9). These histone modifications correlate with either active chromatin, in the case of $\mathrm{H3}-\mathrm{Ac}-\mathrm{K} 9$, or inactive chromatin, in the case of H3-diME-K9 (Berger 2001; Turner 2002). We first examined nurse cells and follicle cells within the Drosophila ovariole. Both of these cell types exhibit distinct staining patterns with antibodies against $\mathrm{H} 3$-diME-K9 and against H3-Ac-K9 (Fig. 2A-D). Anti-H3-diME-K9 predominantly stains one discrete region near the periphery of each nurse or follicle cell nucleus (Fig. 2A,C). In contrast, anti-H3-AcK9 stains most of the nucleoplasm in both nurse and follicle cells (Fig. 2B,D). Immunostaining with a monoclonal antibody against dMyc shows a distribution similar to the nucleoplasmic staining with anti-H3-Ac-K9 (Fig. $2 \mathrm{~A}^{\prime}-\mathrm{D}^{\prime}$ ). This is confirmed in the merged images shown in Figure $2 \mathrm{~A}^{\prime \prime}-\mathrm{D}^{\prime \prime}$ : dMyc largely overlaps with H3-Ac-K9 but shows diminished overlap or exclusion from areas occupied by H3-diME-K9.

$\mathrm{dMyc}$ is known to be expressed during oogenesis in Drosophila, and hypomorphic mutations in dmyc result in degeneration of the ovaries (Gallant et al. 1996). Figure 2E-E" shows H3-Ac-K9 and dMyc at several stages of ovary development. As shown previously, dMyc can be detected in the germarium, one of the earliest stages in oogenesis (Fig. 2E', asterisk). H3-Ac-K9 can also be detected at this stage and partly overlaps with $\mathrm{dMyc}$ expression (Fig. 2E-E"). At later stages, both dMyc and H3-Ac-K9 levels appear to diminish but then increase at more advanced stages where they are both evident in nurse and follicle cells. dMyc and H3-Ac-K9 can be detected in follicle cells at late stages (note intense overlap in the peripherally staining cells in Fig. 2E"). Although dMyc remains detectable in later-stage nurse cells, H3Ac-K9 staining is markedly diminished at later stages. However, the oocyte nucleus appears to have high H3Ac-K9 levels but almost no detectable dMyc. Therefore, although $\mathrm{H} 3-\mathrm{Ac}-\mathrm{K} 9$ and dMyc staining are coincident in many situations, they can be uncoupled. These changes are consistent with the predicted periods of high and low transcriptional activity during oogenesis. One possibility is that even transient dMyc expression could act to generate a more stable state of increased acetylation. Our results indicate that dMyc is frequently associated with active chromatin, but the relationship between $\mathrm{dMyc}$ and $\mathrm{H} 3-\mathrm{Ac}-\mathrm{K} 9$ is dynamic. 

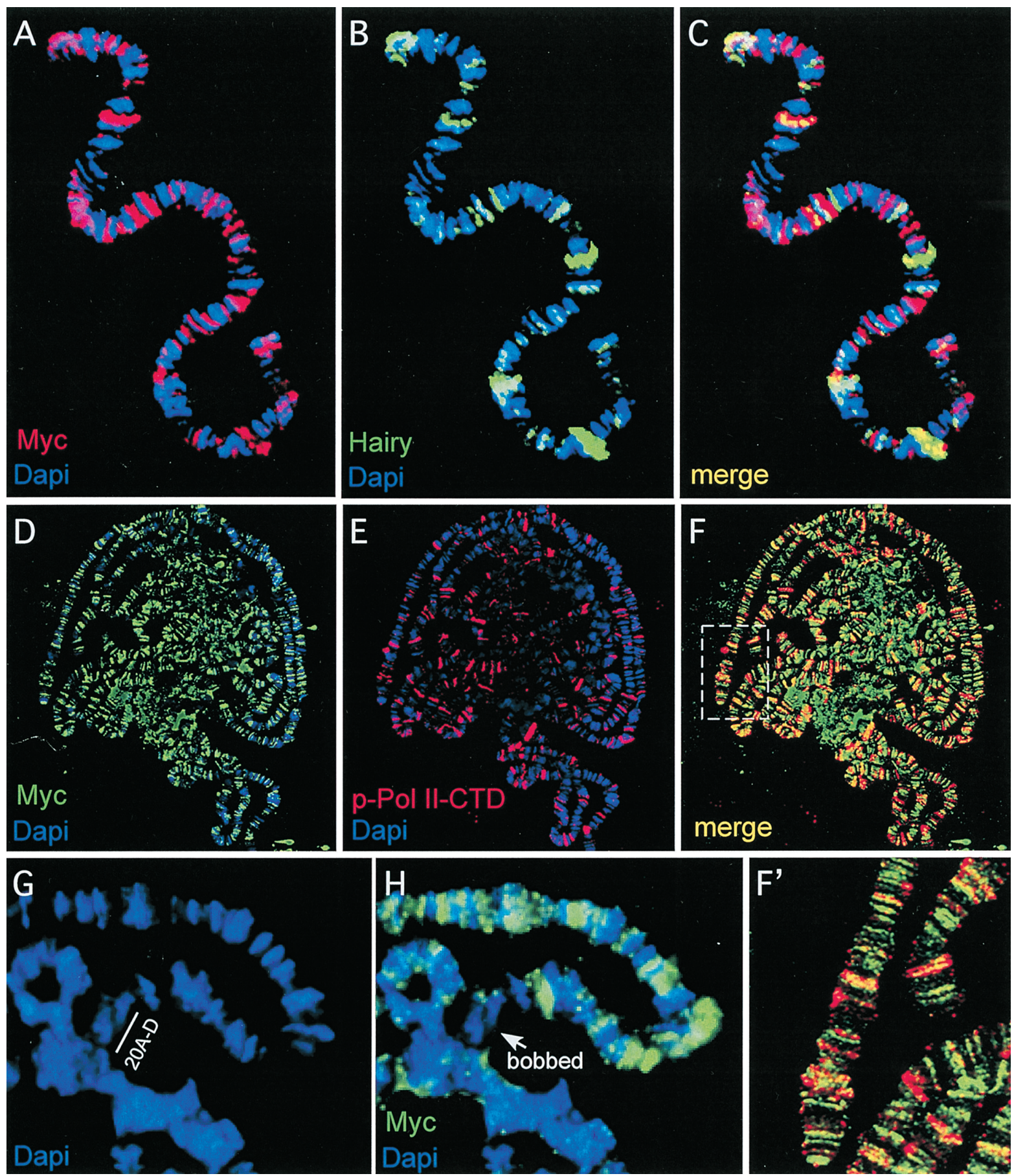

Figure 1. Analysis of the genomic loci bound by dMyc, Hairy, and phospho-RNA polymerase II. ( $A-C$ ) Immunostaining of dMyc (red) and Hairy (green) on third-instar larval salivary gland polytene chromosome sets counterstained with DAPI (blue) to visualize the chromosomes. $(D-F)$ Binding of dMyc (green) and p-Pol-II CTD (red; antibody directed against p-Ser5 CTD PolII). $\left(F^{\prime}\right)$ Higher magnification of the rectangle depicted in $F$. $(G-H)$ Myc does not bind to the rDNA locus "bobbed" (20F). ( $G)$ Higher magnification of X chromosomal arm regions 17-20 counterstained with DAPI (blue) to visualize the chromosomes. $(H)$ Myc binding (green) and DAPI (blue), the rDNA locus "bobbed" is indicated by arrow.

\section{dMyc IS NOT ASSOCIATED WITH THE bobbed rDNA LOCUS}

The DamID study and expression microarray analysis indicate that $\mathrm{dMyc}$ binds to multiple sites in the genome in a manner that is associated with transcriptional stimulation of many genes (Orian et al. 2003). In general, most of the genes analyzed in both Drosophila and mammalian systems are those transcribed by RNA polymerase II. However, recent work in mammalian cells has provided evidence that among the genes regulated by cMyc are those that are also transcribed by RNA polymerase I and III. Stimulation of transcription of a subset of small RNAs, many of which are involved in transla- 

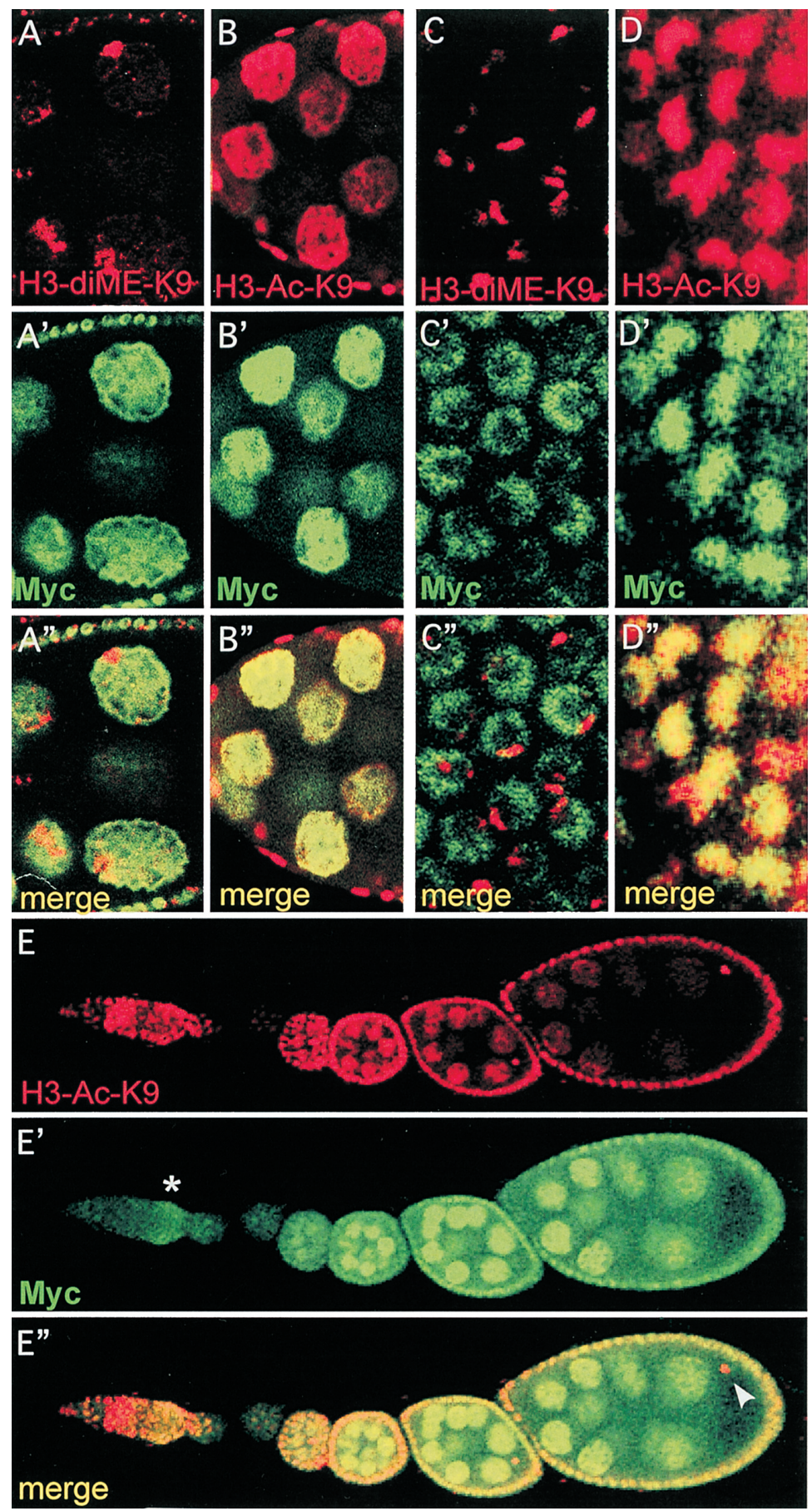

Figure 2. Myc occupies genomic regions that correlate with active chromatin. Immunostaining of Drosophila nurse cells $\left(A-B^{\prime}\right)$, follicle cells $\left(C-D^{\prime \prime}\right)$, and during oogenesis $\left(E-E^{\prime \prime}\right)$. $\left(A-A^{\prime \prime}, C-C^{\prime \prime}\right)$ dMyc binding is excluded from genomic loci associated with inactive genes. dMyc expression is depicted in green. H3diME-K9, a marker of inactive chromatin, is shown in red. The lack of overlap in expression is shown in the merged image (lack of yellow staining; $\left.\mathrm{A}^{\prime \prime}, \mathrm{C}^{\prime \prime}\right) .\left(B-B^{\prime \prime}, D-D^{\prime \prime}\right) \mathrm{dMyc}$ binding correlates with genomic regions associated with active chromatin. dMyc expression is depicted in green. H3-Ac-K9, a marker of active chromatin, is shown in red. The overlap in expression is shown in the merged image (extensive yellow staining; $\left.\mathrm{B}^{\prime \prime}, \mathrm{D}^{\prime \prime}\right)$. $\left(E-E^{\prime \prime}\right)$ The pattern of Ac-H3-K9 (red; E) correlates with dMyc protein expression (green; $E^{\prime}$ ) during Drosophila oogenesis. dMyc expression is observed early in the germarium $(*)$. Regions of overlapping expression are depicted in yellow (merged image; $\left.E^{\prime \prime}\right)$. The oocyte nucleus is highly acetylated and is marked by a white arrow $\left(E^{\prime \prime}\right)$. tion, mediated by RNA polymerase III occurs through association of c-Myc protein with the basal transcription machinery and does not involve direct binding of Myc protein to DNA (Gomez-Roman et al. 2003). In contrast, c-Myc can be detected in nucleoli and binds to multiple E-box sites clustered within the human rDNA regulatory regions and interacts directly with the SL1 subunits of the RNA polymerase I complex, resulting in a marked stimulation of rRNA transcription (Arabi et al. 2005; Grandori et al. 2005). In mammalian cells there is also evidence that c-Myc regulates rRNA abundance indirectly through such targets as UBF (Poortinga et al.
2004), fibrillarin (Coller et al. 2000), and Bop1 (Holzel et al. 2005).

In Drosophila, dMyc has been shown to be required for rRNA synthesis and ribosome biogenesis during larval development. However, no direct binding of dMyc to Drosophila rDNA genes is detected in DamID analysis or chromatin immunoprecipitation experiments (Grewal et al. 2005; S. Grewal, pers. comm.). Instead, it appears that dMyc indirectly regulates fly rDNA expression entirely through up-regulated transcription of target genes that are involved in ribosome biogenesis. These include the critical RNA-polymerase-I-associated factor dTIF-IA and the 
second largest subunit of RNA polymerase I, RpI135, as well as multiple genes involved in rRNA processing and ribosomal proteins (Grewal et al. 2005).

Consistent with the above findings, our immunostaining of Drosophila polytene chromosomes failed to detect association of dMyc with the rRNA encoding bobbed locus in the $20 \mathrm{~F}$ region of the $\mathrm{X}$ chromosome. This lack of $\mathrm{dMyc}$ binding is striking, especially considering the extensive association of $\mathrm{dMyc}$ with regions adjacent to bobbed on the same chromosome (Fig. 1G,H). It is important to note that rDNA is actively transcribed in salivary glands at this stage of larval development (Karpen et al. 1988). These data underscore an interesting divergence of molecular function between the Drosophila and mammalian Myc proteins. In both systems, Myc proteins control ribosome biogenesis indirectly by influencing expression of genes involved in rRNA transcription and processing and its assembly into ribosomes. However, in mammalian cells c-Myc has acquired the additional function of stimulating pre-rRNA abundance through direct association with the RNA polymerase I transcriptional apparatus. Because Drosophila rDNA genes lack canonical E-boxes (Grewal et al. 2005), whereas mammalian rDNA genes contain multiple E-boxes (Arabi et al. 2005; Grandori et al. 2005), it is possible that mammalian rDNA transcription units have evolved to take advantage of c-Myc transcriptional activity.

\section{dMnt INHIBITS rRNA TRANSCRIPTION}

As described above, our DamID analysis demonstrated a striking overlap between binding sites for $\mathrm{dMyc}$ and dMnt. dMnt is the single Drosophila ortholog of mammalian Mxd/Mnt proteins (Orian et al. 2003). This is consistent with limited chromatin immunoprecipitation data in mammalian cells which demonstrated that c-Myc and Mxd1 (Mad1) have the same binding sites in the cyclin D2 promoter (Bouchard et al. 2001). In addition, T cells overexpressing Mxd1 were found to down-regulate a large number of genes, $80 \%$ of whose expression was previously known to be up-regulated by Myc (Iritani et al. 2002). Indeed, there is considerable evidence that mammalian Mxd/Mnt and Drosophila dMnt proteins antagonize Myc's biological functions relating to growth, proliferation, transformation, and apoptosis (Lahoz et al. 1994; Cerni et al. 1995; Chen et al. 1995; Koskinen et al. 1995; Roussel et al. 1996; Loo et al. 2005). This antagonism is likely to occur in part through competition for available Max protein and for E-box-binding sites (Walker et al. 2005), as well as through the opposing transcriptional activities of Myc-Max and Mxd-Max heterodimers. The transcriptional repression activity of Mxd and Mnt proteins is mediated by association with $\mathrm{mSin} 3-$ HDAC corepressor complexes (for review, see Ayer 1999; Knoepfler and Eisenman 1999), and the sole Drosophila homolog, dMnt, has been shown to bind $\mathrm{dSin} 3$ and to function as a repressor at promoter-proximal E-boxes (Loo et al. 2005).

Because dMyc stimulation of rRNA transcription is a critical function related to cell and organismal growth in

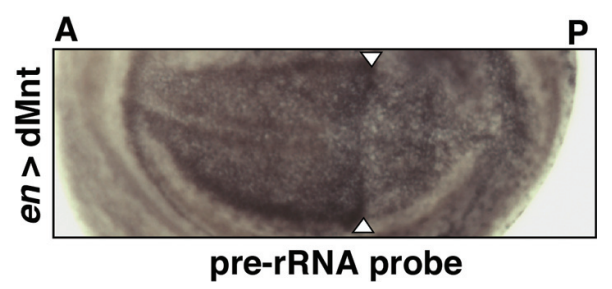

Figure 3. dMnt inhibits rRNA synthesis. An en-Gal4 driver was used to express a dMnt transgene in the posterior $(P$; right half $)$ compartments of wing imaginal discs. Wing discs were analyzed for levels of pre-rRNA by in situ hybridization using a probe to the internal transcribed spacer (ITS1) region of the precursor RNA. The arrowheads represent the A-P posterior border, posterior to the right.

Drosophila, we tested whether dMnt would abrogate rRNA transcription. UAS-dMnt was expressed as a transgene under control of an engrailed-Gal4 driver. This driver results in dMnt transgene expression in the posterior compartment $(\mathrm{P})$ of the wing imaginal disc. The amount of rRNA transcription is assessed by in situ hybridization with a probe to the internal transcribed spacer region which only detects the uncleaved precursor rRNA. Because the engrailed driver is not expressed in the anterior portion (A) of the disc, this region serves as a control. Figure 3 shows that the levels of pre-rRNA signal are markedly lower throughout the posterior compartment. These findings indicate that expression of dMnt results in down-regulation of pre-rRNA synthesis, consistent with the notion that dMnt antagonizes dMyc's growth-stimulatory effects (Loo et al. 2005). More detailed expression array analysis will be required to determine specifically which dMyc targets are down-regulated by dMnt expression.

\section{CONCLUSIONS}

We have presented evidence suggesting that the Drosophila dMyc transcription factor exhibits widespread binding to Drosophila genomic DNA and that many binding sites are associated with actively transcribed regions of chromatin. This was initially demonstrated in the DamID analysis, which indicated that dMax network proteins associate with approximately $15 \%$ of Drosophila coding regions on all four major chromosomes (Orian et al. 2003). We surmise that this number is likely to be an underestimate because our approach only detected binding regions located within coding regions and would have excluded intronic and intergenic regions. Our immunostaining of polytene chromosomes shown in Figure 1 provides further support for this idea, since nearly all interband regions appear to be associated with dMyc. Additionally, a majority of regions with actively transcribing RNA polymerase II coincide with the anti$\mathrm{dMyc}$ stained areas, a result consistent with expression array analysis showing that nearly half of $\mathrm{dMyc}$-binding sites correspond to genes whose expression is regulated by dMyc (Orian et al. 2003).

Evidence that $\mathrm{dMyc}$ binding and gene regulation are widespread has not been confined to Drosophila. Chromatin immunoprecipitation assays in human cells have 
shown that c-Myc is associated with $8-10 \%$ of coding regions and that many of these regions display augmented histone acetylation (Fernandez et al. 2003). Furthermore, array analyses of chromatin immunoprecipitates (ChIPchip) have confirmed widespread binding by Myc (Cawley et al. 2004; Li et al. 2003), leading to a prediction of 24,000 binding sites in the human genome for $\mathrm{c}-\mathrm{Myc}$ (Cawley et al. 2004).

The nuclear staining experiments shown in Figure 2 also provide support for the view that $\mathrm{dMyc}$ is largely present in active regions of chromatin. dMyc immunostaining occurs throughout the nucleoplasm, coinciding with H3-Ac-K9, a mark of active chromatin. Importantly, the pericentric heterochromatic regions of the nucleus marked by H3-diMe-K9 are devoid of dMyc staining. Therefore, the DamID studies, and the chromosomal and nuclear immunostaining experiments together, argue that $\mathrm{dMyc}$ binding is widespread and correlates with active gene expression. It is important to note, however, that significant amounts of dMyc chromosomal staining do not overlap with anti-phospho-CTD RNA polymerase II immunostained regions (Fig. 1D-F), raising the possibility that dMyc can occupy specific sites which are not undergoing active transcription. Such sites may represent regions that, although transcriptionally inactive, have the potential to be activated or require a component not dependent on the phospho-CTD. Alternatively, they may simply be sites that dMyc occupies without exerting a transcriptional response.

Taken together, the evidence relating to widespread binding and gene activation by both Drosophila and mammalian Myc proteins prompts a reassessment of Myc protein function. The view that Myc functions as a standard transcription factor targeting a discrete subset of genes is unlikely to be correct. Instead, Myc can perhaps be considered as a more global DNA-binding protein affecting the transcription or the transcriptional potential of a large number of genes. This view is consistent with the very profound effects on cellular behavior and oncogenesis associated with Myc expression, in that its proximity to such a large number of coding regions implies a direct regulation of many targets, particularly those involved in cell growth. Although less is known about the Mxd/Mnt proteins, our DamID data and the strong effects of dMnt expression on rRNA synthesis make it likely that Mxd/Mnt antagonize Myc activity at many gene targets. To what extent the difference in the ability of vertebrate and invertebrate Myc proteins to directly regulate rRNA transcription accounts for the ability of vertebrate Myc proteins to regulate proliferation and oncogenesis in addition to growth remains an open question. Another important question now under study is whether the widespread binding of Myc occurs as a result of changes in chromatin structure or whether Myc binding itself acts to dictate chromatin structure over large regions of the genome.

\section{ACKNOWLEDGMENTS}

We are grateful to Julio Vazquez (Scientific Imagining Facility) and Jeffrey Delrow (Genomics Facility) for dis- cussion, advice, and assistance. This work was supported by grants from the National Institutes of Health to R.N.E. (RO1CA57138), S.M.P. (RO1GM073021), and B.A.E. (RO1 GM51186). A.O. was supported by the Human Frontiers Science Program (CDA 0048/2004C). A.O. and P.S.K. are Special Fellows of the Lymphoma and Leukemia Society. S.S.G. was supported by a research fellowship from the SASS Foundation for Medical Research. R.N.E. is an American Cancer Society Research Professor.

\section{REFERENCES}

Adhikary S. and Eilers M. 2005. Transcriptional regulation and transformation by Myc proteins. Nat. Rev. Mol. Cell Biol. 6: 635.

Amati B., Frank S.R., Donjerkovic D., and Taubert S. 2001. Function of the c-Myc oncoprotein in chromatin remodeling and transcription. Biochim. Biophys. Acta 1471: M135.

Arabi A., Wu S., Shiue C., Ridderstrale K., Larsson L.-G., and Wright A.P.H. 2005. c-Myc associates with ribosomal DNA in the nucleolus and activates RNA polymerase I transcription. Nat. Cell Biol. 7: 303.

Ayer D.E. 1999. Histone deacetylases: Transcriptional repression with SINers and NuRDs. Trends Cell Biol. 9: 193.

Ayer D.E., Lawrence Q.A., and Eisenman R.N. 1995. Mad-Max transcriptional repression is mediated by ternary complex formation with mammalian homologs of yeast repressor Sin3. Cell 80: 767.

Berger S.L. 2001. Molecular biology. The histone modification circus. Science 292: 64.

Bianchi-Frias D., Orian A., Delrow J.J., Vazquez J., RosalesNieves A.E., and Parkhurst S.M. 2004. Hairy transcriptional repression targets and cofactor recruitment in Drosophila. PLoS Biol. 2: E178.

Bouchard C., Dittrich O., Kiermaier A., Dohmann K., Menkel A., Eilers M., and Luscher B. 2001. Regulation of cyclin D2 gene expression by the Myc/Max/Mad network: Myc- dependent TRRAP recruitment and histone acetylation at the cyclin D2 promoter. Genes Dev. 15: 2042.

Brenner C., Deplus R., Didelot C., Loriot A., Vire E., De Smet C., Gutierrez A., Danovi D., Bernard D., Boon T., Pelicci P. G., Amati B., Kouzarides T., de Launoit Y., Di Croce L., and Fuks F. 2005. Myc represses transcription through recruitment of DNA methyltransferase corepressor. EMBO J. 24: 336.

Brubaker K., Cowley S.M., Huang K., Loo L., Yochum G.S., Ayer D.E., Eisenman R.N., and Radhakrishnan I. 2000. Solution structure of the interacting domains of the Mad-Sin3 complex: Implications for recruitment of a chromatin-modifying complex. Cell 103:655.

Cawley S., Bekiranov S., Ng H.H., Kapranov P., Sekinger E.A., Kampa D., Piccolboni A., Sementchenko V., Cheng J., Williams A.J., Wheeler R., Wong B., Drenkow J., Yamanaka M., Patel S., Brubaker S., Tammana H., Helt G., Struhl K., and Gingeras T.R. 2004. Unbiased mapping of transcription factor binding sites along human chromosomes 21 and 22 points to widespread regulation of noncoding RNAs. Cell 116: 499.

Cerni C., Bousset K., Seelos C., Burkhardt H., Henriksson M., and Luscher B. 1995. Differential effects by Mad and Max on transformation by cellular and viral oncoproteins. Oncogene 11: 587 .

Chen J., Willingham T., Margraf L.R., Schreiber-Agus N., DePinho R.A., and Nisen P.D. 1995. Effects of the MYC oncogene antagonist, MAD, on proliferation, cell cycling and the malignant phenotype of human brain tumor cells. Nat. Med. 1: 638 .

Cole M.D. and Nikiforov M.A. 2006. Transcriptional activation by the Myc oncoprotein. Curr. Top. Microbiol. Immunol. 302: (in press).

Coller H.A., Grandori C., Tamayo P., Colbert T., Lander E.S., Eisenman R.N., and Golub T.R. 2000. Expression analysis 
with oligonucleotide microarrays reveals MYC regulates genes involved in growth, cell cycle, signaling, and adhesion. Proc. Natl. Acad. Sci. 97: 3260.

Cowley S.M., Kang R.S., Frangioni J.V., Yada J.J., DeGrand A.M., Radhakrishnan I., and Eisenman R.N. 2004. Functional analysis of the Mad1-mSin3A repressor-corepressor interaction reveals determinants of specificity, affinity, and transcriptional response. Mol. Cell. Biol. 24: 2698.

Eisenman R.N. 2001. Deconstructing myc. Genes Dev. 15: 2023.

Fernandez P.C., Frank S.R., Wang L., Schroeder M., Liu S., Greene J., Cocito A., and Amati B. 2003. Genomic targets of the human c-Myc protein. Genes Dev. 17: 1115.

Frank S.R., Schroeder M., Fernandez P., Taubert S., and Amati B. 2001. Binding of c-Myc to chromatin mediates mitogen-induced acetylation of histone $\mathrm{H} 4$ and gene activation. Genes Dev. 15: 2069.

Gallant P. 2006. Myc/Max/Mad in invertebrates. The evolution of the Max network. Curr. Top. Microbiol. Immunol. 302: (in press).

Gallant P., Shiio Y., Cheng P.F., Parkhurst S., and Eisenman R.N. 1996. Myc and Max homologs in Drosophila. Science 274: 1523 .

Gomez-Roman N., Grandori C., Eisenman R.N., and White R.J. 2003. Direct activation of RNA polymerase III transcription by c-Myc. Nature 421: 290.

Grandori C., Cowley S.M., James L.P., and Eisenman R.N. 2000. The MYC/MAX/MAD network and the transcriptional control of cell behavior. Annu. Rev. Cell Dev. Biol. 16: 653.

Grandori C., Gomez-Roman N., Felton-Edkins Z.A., Ngouenet C., Galloway D.A., Eisenman R.N., and White R.J. 2005. cMyc binds to human ribosomal DNA and stimulates transcription of rRNA genes by RNA polymerase I. Nat. Cell Biol. 7: 311 .

Greil F., van der Kraan I., Delrow J., Smothers J.F., de Wit E., Bussemaker H.J., van Driel R., Henikoff S., and van Steensel B. 2003. Distinct HP1 and Su(var)3-9 complexes bind to sets of developmentally coexpressed genes depending on chromosomal location. Genes Dev. 17: 2825.

Grewal S.S., Li L., Orian A., Eisenman R.N., and Edgar B.A. 2005. Myc-dependent regulation of ribosomal RNA synthesis during Drosophila development. Nat. Cell Biol. 7: 295.

Henriksson M. and Luscher B. 1996. Proteins of the Myc network: Essential regulators of cell growth and differentiation. Adv. Cancer Res. 68: 109.

Herold S., Wanzel M., Beuger V., Frohme C., Beul D., Hillukkala T., Syvaoja J., Saluz H.P., Haenel F., and Eilers M. 2002. Negative regulation of the mammalian UV response by Myc through association with Miz-1. Mol. Cell 10: 509.

Holzel M., Rohrmoser M., Schlee M., Grimm T., Harasim T., Malamoussi A., Gruber-Eber A., Kremmer E., Hiddemann W., Bornkamm G.W., and Eick D. 2005. Mammalian WDR12 is a novel member of the Pes1-Bop1 complex and is required for ribosome biogenesis and cell proliferation. J. Cell Biol. 170: 367.

Iritani B.M., Delrow J., Grandori C., Gomez I., Klacking M., Carlos L.S., and Eisenman R.N. 2002. Modulation of T-lymphocyte development, growth and cell size by the Myc antagonist and transcriptional repressor Mad1. EMBO J. 21: 4820 .

Johnston L.A., Prober D.A., Edgar B.A., Eisenman R.N., and Gallant P. 1999. Drosophila myc regulates growth during development. Cell 98: 779.

Karpen G.H., Schaefer J.E., and Laird C.D. 1988. A Drosophila rRNA gene located in euchromatin is active in transcription and nucleolus formation. Genes Dev. 2: 1745.

Kim S.Y., Herbst A., Tworkowski K.A., Salghetti S.E., and Tansey W.P. 2003. Skp2 regulates myc protein stability and activity. Mol. Cell 11: 1177.

Kleine-Kohlbrecher D., Adhikary S., and Eilers M. 2006. Mechanisms of transcriptional repression by Myc. Curr. Top. Microbiol. Immunol. 302: (in press).

Knoepfler P.S. and Eisenman R.N. 1999. Sin meets NuRD and other tails of repression. Cell 99: 447
Koskinen P.J., Ayer D.E., and Eisenman R.N. 1995. Repression of Myc-Ras co-transformation by Mad is mediated by multiple protein-protein interactions. Cell Growth Differ. 6: 623.

Lahoz E.G., Xu L., Schreiber-Agus N., and DePinho R.A. 1994. Suppression of Myc, but not E1a, transformation activity by Max-associated proteins, Mad and Mxi1. Proc. Natl. Acad. Sci. 91: 5503.

Li Z., Van Calcar S., Qu C., Cavenee W.K., Zhang M.Q., and Ren B. 2003. A global transcriptional regulatory role for cMyc in Burkitt's lymphoma cells. Proc. Natl. Acad. Sci. 100: 8164.

Loo L.W., Secombe J., Little J.T., Carlos L.S., Yost C., Cheng P.F., Flynn E.M., Edgar B.A., and Eisenman R.N. 2005. The transcriptional repressor dMnt is a regulator of growth in Drosophila melanogaster. Mol. Cell. Biol. 25: 7078.

Luscher B. 2001. Function and regulation of the transcription factors of the Myc/Max/Mad network. Gene 277: 1.

Lutz W., Leon J., and Eilers M. 2002. Contributions of Myc to tumorigenesis. Biochim. Biophys. Acta 1602: 61.

Maines J.Z., Stevens L.M., Tong X., and Stein D. 2004. Drosophila $\mathrm{dMyc}$ is required for ovary cell growth and endoreplication. Development 131: 775.

Moberg K.H., Mukherjee A., Veraksa A., Artavanis-Tsakonas S., and Hariharan I.K. 2004. The Drosophila F box protein archipelago regulates dMyc protein levels in vivo. Curr. Biol. 14: 965.

Nesbit C.E., Tersak J.M., and Prochownik E.V. 1999. MYC oncogenes and human neoplastic disease. Oncogene 18: 3004.

Orian A., van Steensel B., Delrow J., Bussemaker H.J., Li L., Sawado T., Williams E., Loo L.M., Cowley S.M., Yost C., Pierce S., Edgar B.A., Parkhurst S.M., and Eisenman R.N. 2003. Genomic binding by the Drosophila Myc, Max, Mad.Mnt transcription factor network. Genes Dev. 17: 1101.

Oster S.K., Ho C.S., Soucie E.L., and Penn L.Z. 2002. The myc oncogene: MarvelouslY Complex. Adv. Cancer Res. 84: 81.

Pierce S.B., Yost C., Britton J.S., Loo L.W., Flynn E.M., Edgar B.A., and Eisenman R.N. 2004. dMyc is required for larval growth and endoreplication in Drosophila. Development 131: 2317.

Poortinga G., Hannan K.M., Snelling H., Walkley C.R., Jenkins A., Sharkey K., Wall M., Brandenburger Y., Palatsides M., Pearson R.B., McArthur G.A., and Hannan R.D. 2004. MAD1 and c-MYC regulate UBF and rDNA transcription during granulocyte differentiation. EMBO J. 23: 3325 .

Popescu N.C. and Zimonjic D.B. 2002. Chromosome-mediated alterations of the MYC gene in human cancer. J. Cell. Mol. Med. 6: 151.

Rottmann S. and Luscher B. 2006. The Mad side of the Max network: Antagonising the function of Myc and more. Curr. Top. Microbiol. Immunol. 302: (in press).

Roussel M.F., Ashmun R.A., Sherr C.J., Eisenman R.N., and Ayer D.E. 1996. Inhibition of cell proliferation by the Mad1 transcriptional repressor. Mol. Cell. Biol. 16: 2796.

Schreiber-Agus N., Stein D., Chen K., Goltz J.S., Stevens L., and DePinho R.A. 1997. Drosophila Myc is oncogenic in mammalian cells and plays a role in the diminutive phenotype. Proc. Natl. Acad. Sci. 94: 1235.

Schreiber-Agus N., Chin L., Chen K., Torres R., Rao G., Guida P., Skoultchi A.I., and DePinho R.A. 1995. An amino-terminal domain of Mxi1 mediates anti-Myc oncogenic activity and interacts with a homolog of the yeast repressor SIN3. Cell 80: 777.

Seoane J., Pouponnot C., Staller P., Schader M., Eilers M., and Massague J. 2001. TGF $\beta$ influences Myc, Miz-1 and Smad to control the CDK inhibitor p15 $5^{\mathrm{INK} 4 \mathrm{~b}}$. Nat. Cell Biol. 3: 400.

Staller P., Peukert K., Kiermaier A., Seoane J., Lukas J., Karsunky H., Möröy T., Bartek J., Massague J., Hänel F., and Eilers M. 2001. Repression of $\mathrm{p} 15^{\mathrm{INK} 4 \mathrm{~b}}$ expression by Myc through association with Miz-1. Nat. Cell Biol. 3: 392.

Trumpp A., Refaeli Y., Oskarsson T., Gasser S., Murphy M., Martin G.R., and Bishop J.M. 2001. c-Myc regulates mammalian body size by controlling cell number but not cell size. Nature 414: 768. 


\section{Myc AND CHROMATIN}

Turner B.M. 2002. Cellular memory and the histone code. Cell 111: 285 .

van Steensel B. and Henikoff S. 2000. Identification of in vivo DNA targets of chromatin proteins using tethered Dam methyltransferase. Nat. Biotechnol.18: 424.

van Steensel B., Delrow J., and Bussemaker H.J. 2003. Genomewide analysis of Drosophila GAGA factor target genes reveals context-dependent DNA binding. Proc. Natl. Acad. Sci. 100: 2580 .

van Steensel B., Delrow J., and Henikoff S. 2001. Chromatin profiling using targeted DNA adenine methyltransferase. Nat. Genet. 27: 304.

von der Lehr N., Johansson S., Wu S., Bahram F., Castell A., Cetinkaya C., Hydbring P., Weidung I., Nakayama K., Nakayama K.I., Soderberg O., Kerppola T.K., and Larsson L.G. 2003. The F-box protein Skp2 participates in c-Myc proteosomal degradation and acts as a cofactor for c-Myc-regulated transcription. Mol. Cell 11: 1189.

Walker W., Zhou Z.Q., Ota S., Wynshaw-Boris A., and Hurlin P.J. 2005. Mnt-Max to Myc-Max complex switching regu- lates cell cycle entry. J. Cell Biol. 169: 405.

Welcker M., Orian A., Grim J.A., Eisenman R.N., and Clurman B.E. 2004a. A nucleolar isoform of the Fbw7 ubiquitin ligase regulates c-Myc and cell size. Curr. Biol. 14: 1852.

Welcker M., Orian A., Jin J., Grim J.A., Harper J.W., Eisenman R.N., and Clurman B.E. 2004b. The Fbw7 tumor suppressor regulates glycogen synthase kinase 3 phosphorylation-dependent cMyc protein degradation. Proc. Natl. Acad. Sci. 101: 9085.

Yada M., Hatakeyama S., Kamura T., Nishiyama M., Tsunematsu R., Imaki H., Ishida N., Okumura F., Nakayama K., and Nakayama K.I. 2004. Phosphorylation-dependent degradation of c-Myc is mediated by the F-box protein Fbw7. EMBO J. 23: 2116.

Zeller K.I., Jegga A.G., Aronow B.J., O’Donnell K.A., and Dang C.V. 2003. An integrated database of genes responsive to the Myc oncogenic transcription factor: Identification of direct genomic targets. Genome Biol. 4: R69.

Zhou Z.Q. and Hurlin P.J. 2001. The interplay between Mad and Myc in proliferation and differentiation. Trends Cell Biol. 11: S10. 


\title{
$8_{8}^{\infty} \mathrm{CSH} \&$ Cold Spring Harbor Symposia SYMPOSIA on Quantitative Biology
}

\section{Genomic Binding and Transcriptional Regulation by the Drosophila Myc and Mnt Transcription Factors}

\author{
A. ORIAN, S.S. GREWAL, P.S. KNOEPFLER, et al.
}

Cold Spring Harb Symp Quant Biol 2005 70: 299-307

Access the most recent version at doi:10.1101/sqb.2005.70.019

References This article cites 63 articles, 27 of which can be accessed free at: http://symposium.cshlp.org/content/70/299.full.html\#ref-list-1

License

Email Alerting Receive free email alerts when new articles cite this article - sign up in Service the box at the top right corner of the article or click here. 